\title{
SIMULATOR PESAWAT MELEWATI VHF OMNIDIRECTIONAL RADIO RANGE (VOR)
}

\author{
Ariawan D. Rachmanto*, Iswanto \\ Prodi Teknik Informatika - Fakultas IImu Komputer dan Informatika \\ Universitas Nurtanio Bandung \\ *Corresponding Author : ariawan@unnur.ac.id.
}

\begin{abstract}
Abstrak. Penerbangan pesawat terbang komersial selalu mengikuti flight plan yang dibuat, flight plan dibuat pilot berdasarkan airways yang sudah ada. Airways menghubungkan antara airport dengan $V O R / D M E$, dimana VOR/DME dalam penerbangan dikenal sebagai peralatan navigasi udara . $V O R / D M E$ diperlukan penerbang supaya tidak kehilangan arah sehingga pesawat dapat terbang ke airport tujuan. Instrument $H S I$ memberikan visualisasi bearing, course, from to dan deviasi VOR/DME tujuan. Informasi dari $H S I$ merupakan informasi yang digunakan pilot untuk sampai ke VOR/DME berikutnya. Tujuan penelitian adalah membuat perangkat lunak simulasi pergerakan pesawat melewati VOR, metode pengembangan perangkat lunak menggunakan model Prototype dengan cara melihat perangkat yang sudah ada. Simulasi dan pemodelan dilakukan dengan meletakkan VOR/DME pada latitude dan longitude sesuai dengan letak di darat, kemudian memodelkan letak VOR/DME menggunakan peta MapX4.5, pesawat dikondisikan terbang pada airport yang ditentukan, instrument $\mathrm{HSI}$ dimodelkan dengan menggunakan GL Studio, dengan menggunakan bahasa pemrograman C\#, data VOR/DME Indonesia dan airport Indonesia disimpan dalam Excell. Hasil perhitungan kemudian divisualisasikan pada instrument $\mathrm{HSI}$, hasil visualisasi instrumen dibandingkan dengan Garmin Integrated Flight Deck (GIFD) Trainer, version 14.01 pada kondisi yang sama.
\end{abstract}

Kata kunci : IFR, VOR/DME, Airways, HSI.

Abstract. Commercial airplane flights always follow the flight plan that was made, the flight plan was made by the pilot based on the existing airways. Airways connects airports with $V O R / D M E$, where VOR/DME in flight are known as air navigation equipment. VOR/DME is needed by a pilot so that he does not lose direction so that the aircraft can fly to the destination airport. The HSI instrument provides visualization of bearing, course, from to and destination $V O R / D M E$ deviations. Information from HSI is information that the pilot uses to get to the next $V O R / D M E$. The purpose of this research is to make an aircraft movement simulation software approaching VOR, a software development method using the Prototype model by looking at existing devices. Simulation and modeling are done by placing VOR/DME at latitude and longitude in accordance with the location on land, then modeling the location of VOR/DME using MapX4.5 map, air conditioned flight at the specified airport, HSI instrument is modeled using GL Studio, using language C \# programming, Indonesian VOR/DME data and Indonesian airports are stored in Excel. The calculation results are then visualized on the HSI instrument, the instrument visualization results are compared with the Garmin Integrated Flight Deck (GIFD) Trainer, version 14.01 under the same conditions.

Keywords: IFR, VOR/DME, Airways, HSI.

\section{PENDAHULUAN}

Pendidikan Pilot (Penerbang) sangat mahal karena dalam pendidikan tersebut tidak hanya dikenalkan secara teori tetapi juga dilakukan praktek terbang. Sebelum terbang dengan pesawat terbang seorang calon penerbang akan diperkenalkan dengan instrumen-instrumen yang digunakan dalam penerbangan. Instrument tersebut ada yang terdapat di darat seperti alat navigasi (Navigation Aids disingkat NavAids), ada juga instrumen yang terdapat dalam cockpit pesawat 
seperti Omni-Bearing Selector (OBS) atau Course Deviation Indicator (CDI), HSI (Horizontal Situation Indicator).

Semua pesawat terbang dilengkapi dengan sistem navigasi agar pesawat dapat sampai airport tujuan dengan selamat. Sistem navigasi penerbangan terdiri dari kumpulan berbagai peralatan navigasi udara yang berguna untuk memberi panduan seperti halnya arah, jarak, kecepatan terhadap suatu bandar udara, ketinggian terhadap daratan, serta peralatan yang berfungsi untuk memberikan panduan pendaratan (landing) ketika cuaca buruk yang kesemuanya itu bertujuan untuk keselamatan dan keamanan penerbangan.

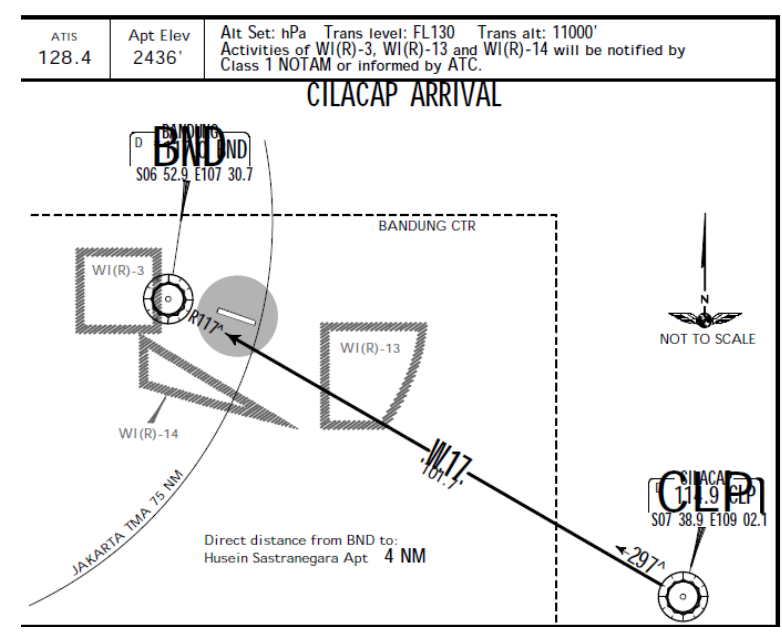

Gambar 1. Kedatangan dari Cilacap

Setiap pesawat terbang yang akan take off atau landing (mendarat) mempunyai panduan yang harus ditaati, pada gambar dibawah ini sebagai contoh pesawat akan mendarat di landasan Husein Sastranegara dengan arah kedatangan dari Cilacap. Setiap pesawat terbang yang take off atau landing mempunyai panduan yang harus ditaati, pada gambar 1 di atas sebagai ilustrasi pesawat akan mendarat di landasan Husein Sastranegara dengan arah kedatangan dari Cilacap. Runway (landasan pacu) bandara Husein Sastranegara mempunyai arah $110^{\circ}$ dan arah sebaliknya $290^{\circ}$ atau biasa ditulis dengan RWY 11/29. Bandara Husein
Sastranegara mempunyai 2 peralatan navigasi udara yaitu VOR/DME dan NDB. VOR/DME untuk bandara Husein dengan kode BND terletak pada koordinat latitude $=-6,882078$ dan longitude $=107,512339$ frekuensi $=117$. Heading pesawat agar dapat mencapai BND harus diarahkan $297^{\circ}$.

Sebelum terbang Pilot berkewajiban memilih atau menentukan rute penerbangannya (flight plan) yang akan dilalui dengan mempertimbangkan perkiraan cuaca (termasuk angin), konsumsi bahan bakar, dan kemampuan (performance) pesawat ${ }^{[10]}$. Flight plan dapat mengikuti airways yang sudah ada, dimana airways ini menghubungkan antara waypoint, waypoint dapat berupa titik-titik yang sudah ditentukan dapat berupa airport, VOR, NDB atau Waypoint yang telah disepakati.

Untuk dapat terbang sesuai dengan flight plan yang telah ditentukan, pilot dapat terbang secara visual (visual flight) atau dengan menggunakan instrument (instrument flight). Terbang instrument adalah dengan menggunakan peralatan navigasi sebagai acuan arah penerbangannya. VOR merupakan alat bantu navigasi jarak sedang, yang bekerja menggunakan frekuensi radio sangat tinggi (VHF/Very High Frequency). VOR memungkinkan pesawat menuju tujuan, dengan memanfaatkan stasiun $V O R$ di darat tanpa tergantung dari keadaan cuaca (yaitu dengan menggunakan bantuan instrument atau dengan bantuan autopilot). Penerbang dapat memanfaatkan stasiun $V O R$ terdekat dengan bandara pada saat tinggal landas kemudian memilih waypoint berikutnya. dapat berupa VOR/DME atau NDB.

Tidak semua VOR dilengkapi dengan $D M E, V O R$ bekerja pada frekuensi VHF dari 108 sampai $117.95 \mathrm{MHz}\left[{ }^{1]}\right.$. VOR adalah alat navigasi udara yang berfungsi memberikan informasi jarak kepada pesawat, sudut miring antara pesawat dan transmiter dari DME. Prinsip kerja 
VOR/DME adalah penerbang melakukan tune frekwensi pada VOR/DME yang menjadi tujuan. Kemudian instrument pesawat akan memberikan informasi bearing, slant range (jarak miring) antara pesawat dengan $V O R$, sehingga dengan informasi tersebut pilot akan tepat ke VOR/DME tujuan. ${ }^{[10]}$

Diperlukan biaya yang besar jika belajar navigasi dengan menggunakan pesawat terbang, sehingga untuk taraf pembelajaran dibuat Simulator VOR yang dapat mensimulasikan pergerakan pesawat yang akan melewati VOR/DME. Simulasi yang dibuat dengan meletakkan (memodelkan) VOR/DME pada tempat/daratan yang dimodelkan pada MapX4.5, posisi latitude dan longitude VOR/DME sesuai dengan letak didaratan, demikian juga pesawat yang akan melewati Navaids ditentukan latitude dan longitudenya dimulai dari airport terdekat. Pada perangkat lunak yang dikembangkan pesawat dapat diatur heading (arah nose pesawat yang dihitung berdasarkan kutub utara), kecepatan pesawat (aircraft speed) juga kecepatan angin (wind speed).

\section{DASAR TEORI}

\subsection{Sistem Navigasi Udara}

Terdapat beberapa peralatan navigasi udara yang digunakan dalam membantu arah penerbangan pesawat, dalam navigasi udara dikenal ada VOR/DME, $N D B$, ILS dan masih banyak lagi. Dalam penelitian ini hanya membuat perangkat lunak simulasi pesawat pada waktu akan dan setelah melewati VOR/DME, hasil perhitungan bearing, course distance divisualisasikan pada model instrument HSI.

Instrument $H S I$ pada pesawat terbang memvisualisasikan bearing, deviasi , course dalam satuan derajat berdasarkan perhitungan dari signal yang diberikan VOR/DME tujuan. Penerbang memanfaatkan stasiun $V O R$ di darat pada saat tinggal landas, setelah mencapai
VOR tujuan, pilot melakukan tune frekwensi pada VOR berikutnya sebagai arah penerbangan begitu seterusnya sampai pesawat mencapai airport tujuan.

Dalam navigasi terbang dikenal istilah heading, magnetic bearing dan relative bearing. Heading adalah sudut arah hidung pesawat yang diukur berdasarkan kutub utara sebagai acuan. Magnetic bearing adalah sudut yang tercipta antara garis lurus pesawat terhadap stasiun peralatan navigasi ( $V O R$ atau $N D B / A D F$ ) dengan garis lurus pesawat dan kutub utara. Relative bearing adalah sudut yang tercipta antara heading pesawat dengan garis lurus antara pesawat dan navigation ground station.

Untuk lebih jelasnya seperti pada gambar di bawah ini[5],

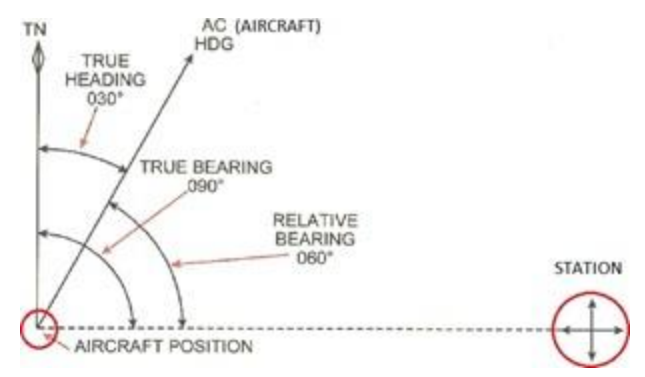

Gambar 2 . Magnetic bearing dan relative bearing

Pada gambar 2 pesawat terbang pada heading $30^{\circ}$, true bearing navaids $90^{\circ}$, bearing pesawat terhadap navaids adalah $60^{\circ}$. Perhitungan sudut dihitung berdasarkan kutub utara.

Posisi atau letak pesawat terbang dan letak VOR/DME dinyatakan dengan Geographic Coordinate System (GCS), yaitu suatu sistem koordinat muka bumi yang direpresentasikan dari permukaan bumi untuk mendefinisikan posisi dipermukaan bumi. Setiap tempat di permukaan bumi di definisikan dengan nilai lintang (latitude) dan bujur (longitude). Satuan koordinatnya adalah derajat.

Jarak diantara posisi pesawat dengan VOR/DME dapat dihitung dengan menggunakan formulasi berikut ${ }^{[3],[10]}$, 


$$
\begin{aligned}
& \text { jarak }=\operatorname{acos}(\sin (\text { lat } 1) * \sin (\text { lat } 2) \\
& +\cos (\text { lat } 1) * \\
& \cos (\text { lat } 2) * \cos (\operatorname{lon} 1-\operatorname{lon} 2)) \\
& \text { bearing }=\bmod \left(\operatorname{atan}^{2}(\sin (\operatorname{lon} 1-\operatorname{lon} 2)\right. \\
& * \cos (\text { lat } 2), \cos (\text { lat } 1) \\
& * \sin (\text { lat } 2)-\sin (\text { lat } 1) \\
& * \cos (\text { lat } 2) \\
& * \cos (\operatorname{lon} 1-\operatorname{lon} 2)), 2 * p i)
\end{aligned}
$$

Menghitung posisi pesawat terbang pada waktu berikutnya dapat dihitung dengan menggunakan :

$$
\begin{aligned}
S W C=\left(\frac{W S}{T A S}\right) * & \sin (W D-C R S) \\
\text { lat }_{\text {new }}=\operatorname{asin}( & \sin (\text { lat } 1) * \cos (\text { jarak }) \\
& +\cos (\text { lat } 1) * \sin (\text { jarak }) \\
& * \cos (\text { bearing })) \\
\text { lon }_{\text {new }}=\bmod & (\text { lon } 1 \\
& -\operatorname{asin}(\sin (\text { bearing }) \\
& * \sin (\text { jarak })) / \cos (\text { lat } 1)) \\
& +(22 / 7), 2 *(22 / 7) \\
& -(22 / 7)
\end{aligned}
$$

Dimana :

lat1 = latitude 1, latitude pesawat.

lon1 = longitude 1 , longitude pesawat .

lat2= latitude 2, latitude VOR.

lon2 = longitude 2, longitude VOR

bearing dalam radian

jarak dalam mile

SWC = Speed, Wind and Course .

\subsection{Sistem Instrument HSI Dalam Pesawat}

Letak stasiun $V O R$ di darat diletakkan sedemikian rupa, VOR digunakan untuk menuntun pesawat menuju bandara tujuan. Dalam penerbangan pilot pesawat terbang dengan bantuan VOR/DME atau dengan menggunakan dua stasiun $V O R$ terdekat. Perlengkapan penerima VOR di pesawat terbang dipergunakan pilot untuk menentukan pergerakan pesawat saat akan melalui VOR/DME, instrument penerima data-data VOR/DME mempunyai 3 macam fungsi/indikator ${ }^{[1][2][9]}$, yaitu :

a. Menentukan azimuth, yaitu sudut searah jarum jam antara arah utara dari stasiun $V O R$ dengan garis yang menghubungkan stasiun tersebut dengan pesawat terbang.

b. Menunjukkan deviasi kepada pilot, yaitu apakah pesawat berada di kiri, kanan atau tepat pada jalur penerbangan yang benar/dipilih. Sehingga dengan mengetahui posisi pesawat terhadap VOR/DME pilot dapat memposisikan pesawat sesuai dengan arah VOR/DME yang akan dilalui.

c. Menunjukkan apakah arah pesawat terbang menuju atau meninggalkan stasiun VOR tujuan.

VOR selalu dilengkapi dengan $D M E$ (Distance Measuring Equipment), adalah alat navigasi udara yang berfungsi memberikan informasi jarak kepada pesawat, jarak yang di berikan adalah sudut miring antara pesawat dan transmiter dari DME ini dan bukan jarak sesungguhnya antara pesawat dan $\mathrm{DME}^{[10]}$.

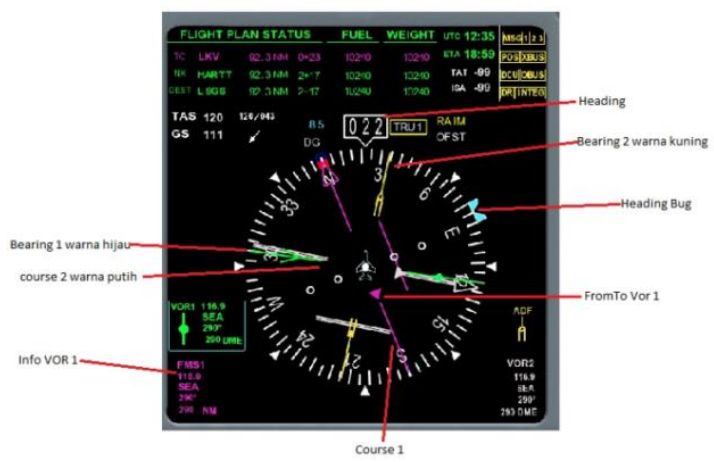

Gambar 3. Instrument HSI Untuk VOR/DME

Instrument yang digunakan untuk menampilkan VOR/DME berupa distance, bearing, course dapat dilihat pada instrument Horizontal Situation Indicator (HSI), seperti pada Gambar $3^{[7]}$. Instrument $\mathrm{HSI}$ tersebut merupakan instrument HSI yang terdapat pada pesawat, terdapat komponen-komponen penting yaitu : 
a. Heading bug yaitu indikator kompas menunjukkan sudut tujuan arah pesawat. Jika diaktifkan, pesawat akan terbang sesuai arah heading bug

b. Bearing adalah sudut antara pesawat terbang dengan VOR/DME tujuan.

c. TO-FROM Indicator menunjukan kepada pilot bahwa bearing yang sudah ditentukan akan membawa pesawat menuju atau meninggalkan VOR station.

d. Aircraft Symbol, Simbol pesawat yang digunakan sebagai referensi, yang akan memberikan informasi lebih dalam penggunaan instrument.

e. Course deviation, digunakan sebagai navigasi pesawat untuk menentukan seberapa besar deviasi posisi lateral pesawat (course) terhadap VOR/DME tujuan, jika lokasi pesawat di sebelah kiri $V O R / D M E$, jarum mengalihkan posisi pesawat ke kanan begitu sebaliknya.

Langkah-langkah pengoperasian sistem navigasi VOR ditunjukkan oleh urutan proses berikut ini ${ }^{[8]}$ :

a. Pilot memilih frekuensi VOR dan memastikan identitas VOR station yang dipilih dengan mendengarkan kode suara dari VOR berupa 3 huruf berupa kode morse.

b. Receiver menerima sinyal RF yang terdiri dari frekuensi carrier dan subcarrier

c. Receiver melakukan proses decoding kepada sinyal yang diterima untuk mengetahui perbedaan fasa diantara keduanya.

d. Setelah perbedaan fase didapatkan, sudut bearing ditentukan kemudian dikirimkan ke indikator dan ditampilkan agar dapat dibaca oleh pilot. Begitu pula dengan TO-FROM indicator-nya.

e. Pilot melanjutkan penerbangan sampai pesawat mencapai titik perpindahan frekuensi (VOR berikutnya). Kemudian pilot memilih
VOR station berikutnya sesuai dengan jalur penerbangannya.

f. Pilot melakukan penerbangan dengan VOR station sebagai acuan sampai pesawat mendekati bandara tujuannya. Setelah mendekati bandara tujuan akhirnya, pilot mengganti frekuensi VOR ke frekuensi ILS (Instrument Landing System) untuk memandu pesawat melakukan pendaratan di runway.

\subsection{Analisis Sistem}

Analisis terhadap sistem peralatan navigasi udara VOR/DME bertujuan untuk mengidentifikasi perilaku sistem dalam hal ini HSI (Horizontal Situation Indicator), cara kerja dan merancang model. Simulasi pergerakan pesawat terbang mendekati $V O R / D M E$ dapat dilihat pada map, heading, course ditampilkan pada model instrument HSI.

Perangkat lunak Simulator VOR yang dikembangkan mempunyai kemampuan sebagai berikut,

a. Pengguna dapat mengatur heading, kecepatan pesawat, course, kecepatan dan arah angin, dengan memutar tombol yang sudah disediakan.

b. Penguna dapat melakukan zoom in dan zoom out, pan tool dan arrow tool pada peta dimana pergerakan pesawat disimulasikan.

c. Pengguna harus menentukan menggunakan $1 \mathrm{VOR} / \mathrm{DME}$ atau 2 VOR/DME pada menu yang telah disediakan, dengan memilih nama VOR/DME.

d. Perangkat lunak menampilkan peta dengan VOR/DME, airways dan airport dimana posisi awal dari pesawat.

e. Perangkat lunak tidak dapat menunjukkan letak VOR/DME pada peta, jika VOR/DME tidak ditentukan atau tidak dipilih terlebih dahulu. 
f. Pengguna dapat menentukan heading pesawat agar menuju ke VOR/DME yang ditentukan atau dipilih.

g. Heading pesawat dapat ditampilkan pada bagian tampilan besaran heading perangkat lunak.

h. Map pada perangkat lunak dapat menampilkan line/garis antara pesawat dengan $V O R / D M E$, baik $V O R$ 1 atau VOR 2.

i. Instrument $\mathrm{HSI}$ dapat menampilkan distance dalam Nm (Nautical Mile) dan bearing (dalam degree) antara pesawat dengan VOR.

j. Pengguna dapat mengubah letak pesawat sesuai dengan data airport yang ada.

k. Pengguna dapat menambah data $V O R / D M E$ dan data airport yang sudah ada.

\section{PERANCANGAN DAN REALISASI}

\subsection{Perancangan Sistem}

Sistem aplikasi yang akan dikembangkan menggunakan MapX 4 untuk tampilan map dengan koordinat airport dan koordinat VOR/DME. Pesawat diterbangkan dari airport terdekat, heading, course dan kecepatan pesawat dapat diatur.

Model instrument $\mathrm{HSI}$ pesawat yang dikembangkan menggunakan GL Studio Version 4.0.9.0, informasi lebih lengkap dapat diakses dari link berikut, https://disti.com/?utm campaign=product domain\&utm source=simulation.com\&utm medium=domain \& $r e f=d p 2$.

Bahasa pemrograman yang digunakan untuk membuat perangkat lunak simulasi adalah C\# Visual Studio 2010. Perancangan perangkat lunak Simulasi dimulai dengan membuat rancangan display perangkat lunak. Jika pada pesawat terbang pemilihan VOR dilakukan dengan tune frekwensi VOR tujuan, dalam perangkat lunak yang dibuat harus ditentukan terlebih dahulu posisi pesawat, $V O R 1$ dan VOR 2. Flowchart dari sistem yang dikembangkan seperti gambar berikut,

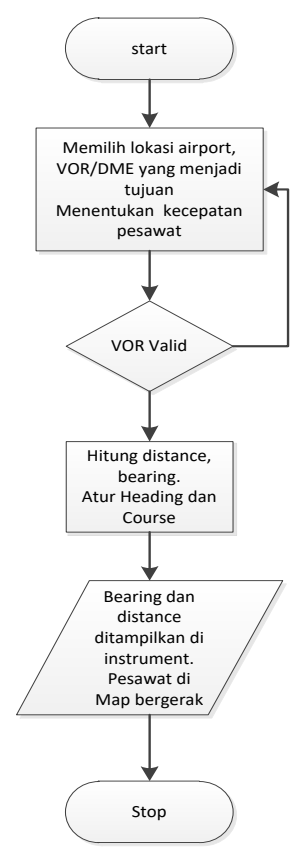

Gambar 4. Flowchart Simulasi VOR/DME

Keterangan gambar 4 VOR1 dan VOR 2 ditentukan terlebih dahulu, jika distance antara pesawat dengan VOR lebih kecil range maka kode VOR muncul di instrument HSI. Sistem menghitung distance dan bearing antara pesawat dengan VOR yang dipilih. Hasil perhitungan di visualisasikan dalam instrumen HSI.

Perancangan perangkat lunak Simulator VOR dapat ditunjukkan seperti pada Gambar 5.

Aplikasi ini terdiri dari 1 antarmuka dengan terdapat data input, data output, maps dan instrument pesawat terbang. Berikut merupakan gambar tampilan antarmuka dari aplikasi yang telah dibuat 

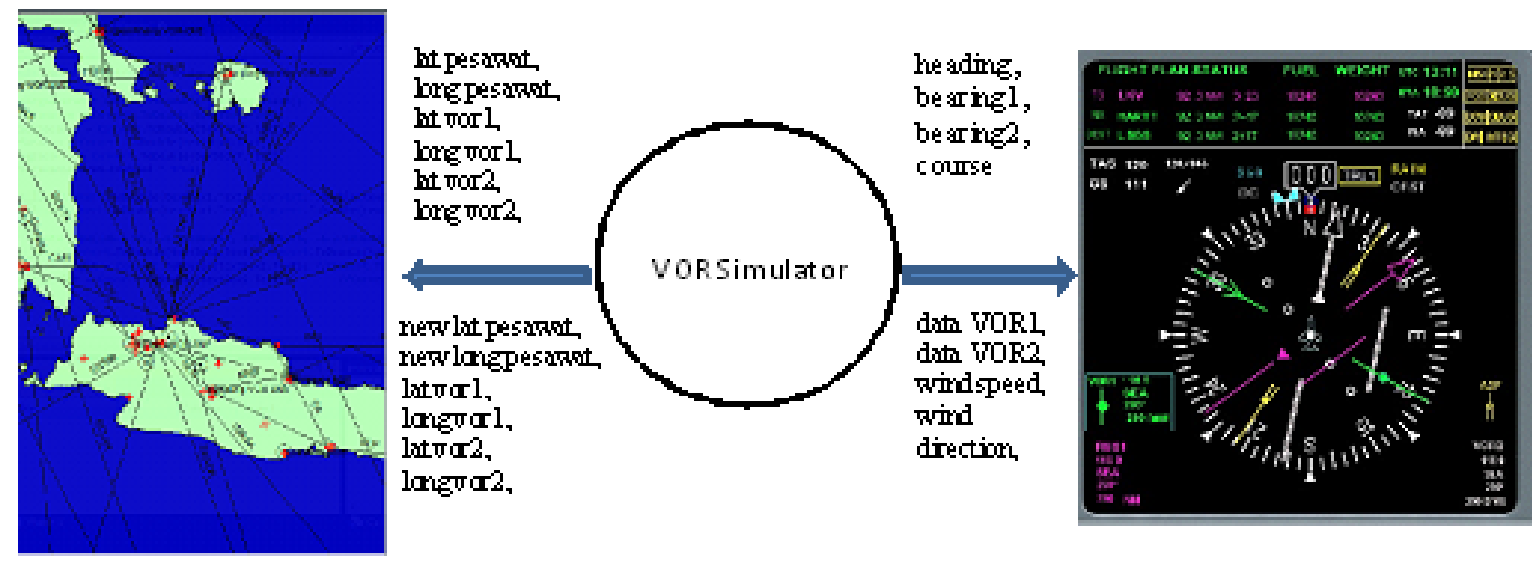

Gambar 5. Design Simulator VOR

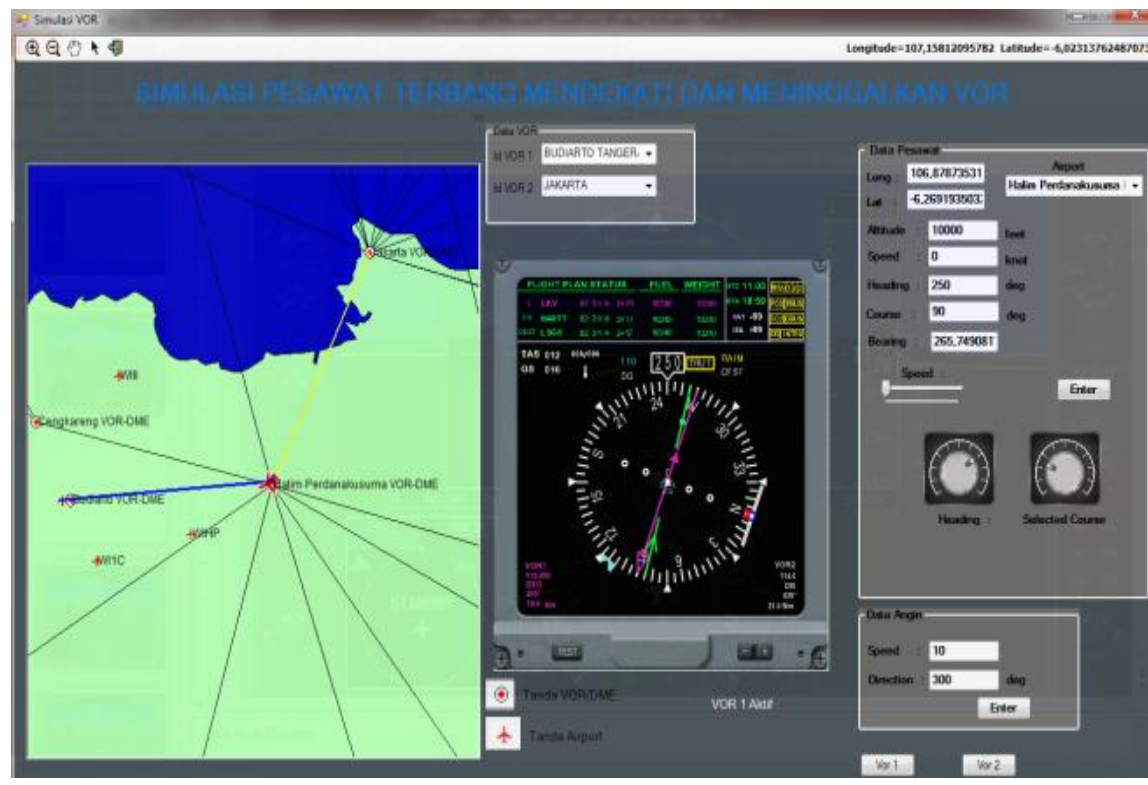

Gambar 6. Tampilan Simulator VOR/DME

Tampilan perangkat lunak dikelompokkan menjadi data pesawat, data angin, map. Data pesawat terdapat data airport(latitude dan longitude), altitude dibuat kontstan, terdapat input yang dapat diatur oleh pengguna seperti speed, heading dan course. Bearing merupakan hasil perhitungan, bearing merupakan sudut antara pesawat dengan VOR/DME. Terdapat pilihan airport pesawat terbang mulai diterbangkan. Data airport dapat diupdate dengan menambah airport Indonesia sesuai dengan format data yang diberikan. Data-data airport yang dipergunakan disesuaikan dengan ketersediaan peta tampilan.

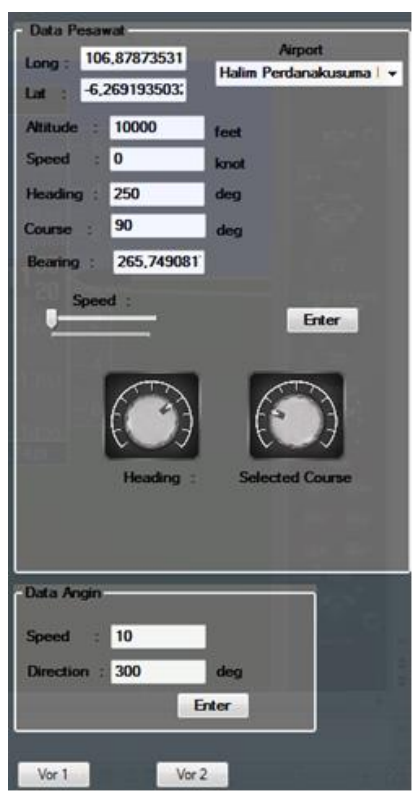

Gambar 7. Data Pesawat Dan Data Angin 
Tabel 1. Keterangan Instrument.

\begin{tabular}{|l|l|}
\hline \multicolumn{1}{|c|}{ Gambar } & \multicolumn{2}{|c|}{ Keterangan } \\
\hline & $\begin{array}{l}\text { Slicer untuk mengatur } \\
\text { Speed pesawat. }\end{array}$ \\
\hline & $\begin{array}{l}\text { Generic knob untuk } \\
\text { mengatur heading pesawat. }\end{array}$ \\
\hline Veneric knob untuk \\
\hline & $\begin{array}{l}\text { Gener } \\
\text { mengatur course pesawat. }\end{array}$ \\
\hline Vor1 & $\begin{array}{l}\text { Button untuk mengaktifkan } \\
\text { Vor 1 dan Vor 2di } \\
\text { instrument EHSI. }\end{array}$ \\
\hline
\end{tabular}

Data VOR merupakan data dari $V O R / D M E$ yang menjadi tujuan pesawat terbang. Dapat digunakan 2 data $V O R / D M E$ dalam hal ini dipilih berdasarkan nama $V O R / D M E$, pada pesawat terbang pilihan $V O R / D M E$ menggunakan frekwensi dari $V O R / D M E$ yang menjadi tujuan, frekwensi VOR/DME Budiarto 115.8 MHz dan DKI Jakarta 114.6.

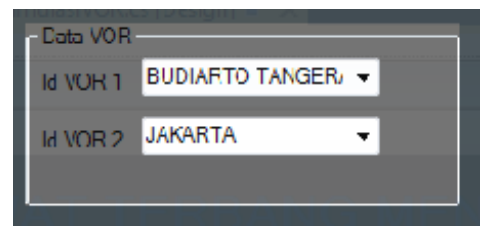

Gambar 8. Data VOR

Terdapat pilihan VOR/DME yang menjadi tujuan pesawat terbang. Data $V O R / D M E$ dapat diupdate dengan menambah VOR/DME di Indonesia sesuai dengan format data yang diberikan. Datadata VOR/DME yang dipergunakan disesuaikan dengan ketersediaan peta tampilan

Instrument EHSI dipergunakan untuk menampilkan data-data hasil perhitungan seperti heading, deviasi, frekwensi VOR/DME, kode VOR/DME, jarak (distance). Pada gambar instrument (Gambar 9.) data VOR 1 ditunjukkan frekwensi 115.8, kode VOR/DME BTO, bearing $265^{\circ}$ jarak $19 \mathrm{Nm}$. Data VOR 2 ditunjukkan frekwensi 114.6, kode VOR/DME DKI, bearing $25^{\circ}$ jarak $21 \mathrm{Nm}$. Pada instrument ditunjukkan bahwa VOR 1 yang aktif. Heading pesawat $250^{\circ}$, course ditunjukkan dengan jarum hijau pada instrument.

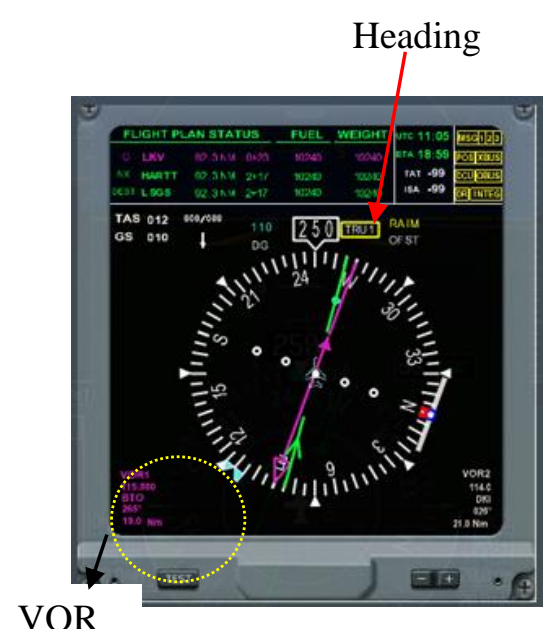

Gambar 9. Instrument EHSI

Pada peta simulasi dapat ditunjukkan pesawat dengan heading $250^{\circ}$, letak VOR/DME Jakarta dan VOR/DME Budiarto. Garis merah dan kuning sebagai garis penghubung antara pesawat terbang dengan VOR/DME yang menjadi tujuan. Peta simulasi seperti pada gambar berikut,

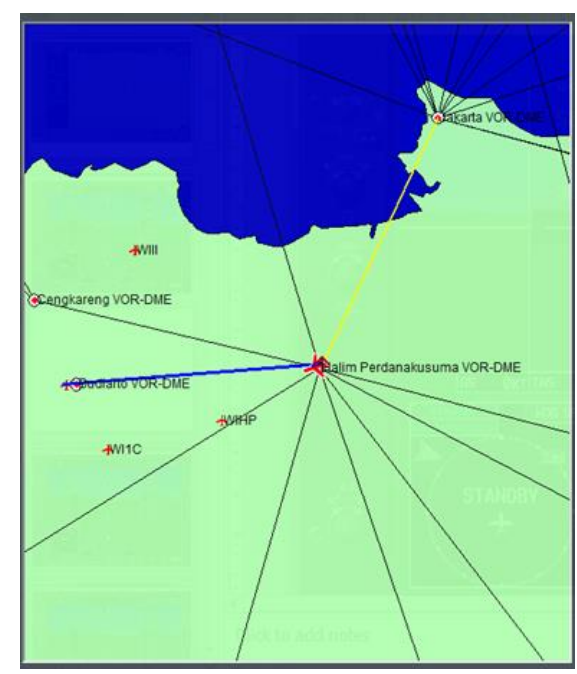

Gambar 10. MAP Simulasi

\section{PENGUJIAN}

Perangkat lunak Simulator VOR dibandingkan dengan perangkat lunak Garmin Integrated Flight Deck (GIFD) Trainer, version 14.01 dibuat oleh Garmin Ltd. Pengujian dilakukan pada airport 
Husein Sastranegara Bandung, heading pesawat $290^{\circ}$.

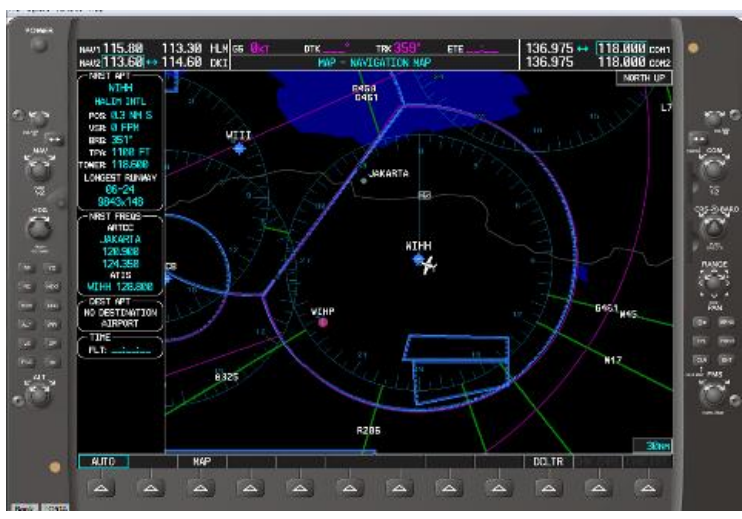

Gambar 11 A. GIFD Trainer- MFD

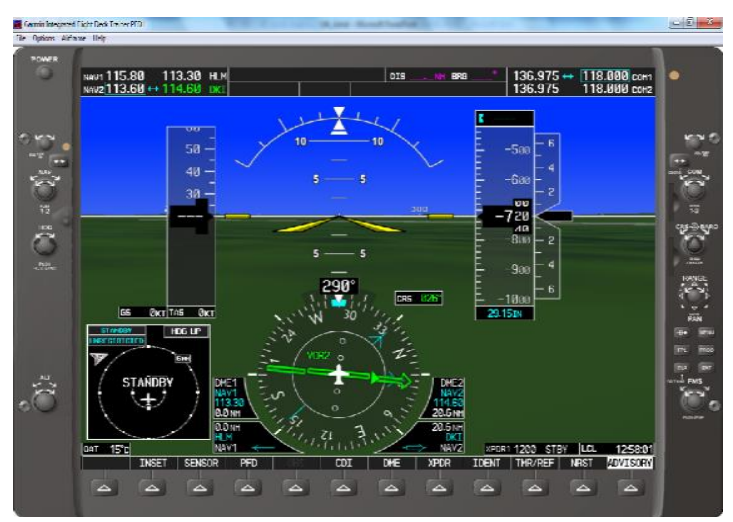

Gambar 11 B. GIFD Trainer- PFD

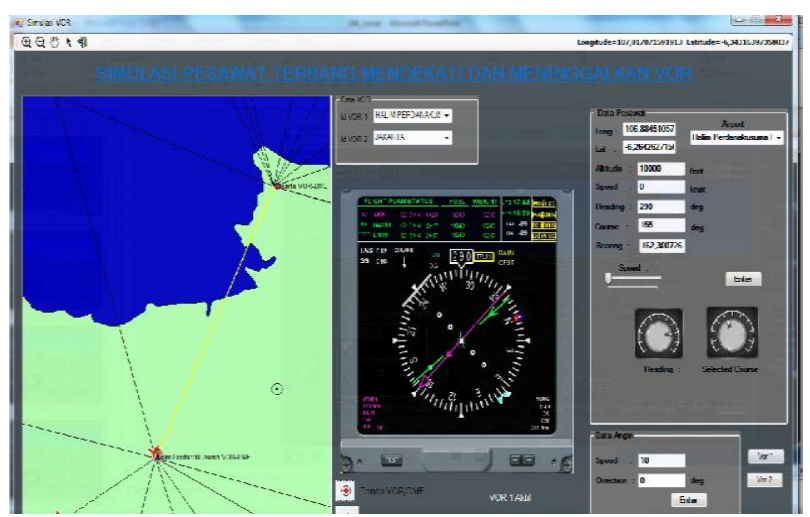

Gambar 12 A. Simulator VOR- HLM

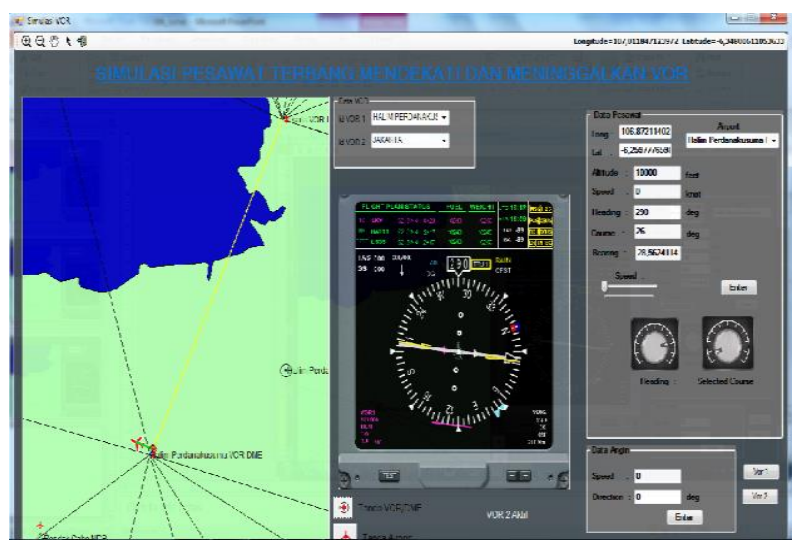

Gambar 12 B. Simulator VOR- DKI

GIFD Trainer terdiri dari tampilan MFD (gambar 11A) dan tampilan PFD (gambar 11B) menunjukkan pesawat berada pada airport Halim Perdanakusuma (WIHH) dengan heading $290^{\circ}$, Vor 1 113.3 HLM bearing terhadap HLM $158^{\circ}$ dan Vor2 114.6 DKI bearing terhadap DKI $26^{\circ}$. Gambar HSI pada instrument PFD menunjukkan Vor 2 (DKI), jarak dari pesawat terhadap DKI 20,6 $\mathrm{Nm}$, sedangkan terhadap HLM $0 \mathrm{Nm}$.

Perangkat lunak Simulator VOR yang dikembangkan ditunjukkan seperti Gambar $12 \mathrm{~A}$ dan $\mathrm{B}$.

Perangkat Simulator VOR yang dikembangkan terdiri dari map, instrument $\mathrm{HSI}$, pengatur heading, course dan speed aircraft. Pada gambar 12A disimulasikan pesawat mulai terbang dari Halim Perdanakusuma dengan heading $290^{\circ}$, dengan menggunakan vor Halim Perdanakusuma (HLM) dan vor Jakarta (DKI) (Gambar 12B). Hasil visualisasi jarak terhadap HLM adalah $0 \mathrm{Nm}$, bearing pesawat terhadap HLM $153^{\circ}$ sedangkan jarak terhadap DKI adalah $21 \mathrm{Nm}$ bearing terhadap DKI $28^{\circ}$. Hasil perbandingan instrument HSI dapat ditunjukkan seperti Gambar 13.

Course pada instrument HSImenunjukkan sebesar $336^{\circ}$ untuk instrument HSI GIFD Trainer, pada instrument $\mathrm{HSI}$ perangkat lunak yang dikembangkan sebesar $336^{\circ}$.

Perangkat Simulator VOR yang dikembangkan diuji mulai terbang pada 
bandara Adi Sucipto (WARJ) dengan heading $280^{\circ}$, dengan menggunakan VOR HLM , untuk kemudian menggunakan VOR CLP setelah melewati JOG. Hasil menggunakan perangkat GIFD Trainer seperti Gambar 14.

Hasil simulasi dengan menggunakan GIFD Trainer jarak pesawat terbang terhadap JOG adalah 7.7 Nm, jarak terhadap CLP adalah 83.6 Nm, bearing pesawat terhadap JOG adalah $263^{\circ}$, bearing terhadap CLP adalah $277^{\circ}$ dapat dilihat dari jarum hijau pada PFD.

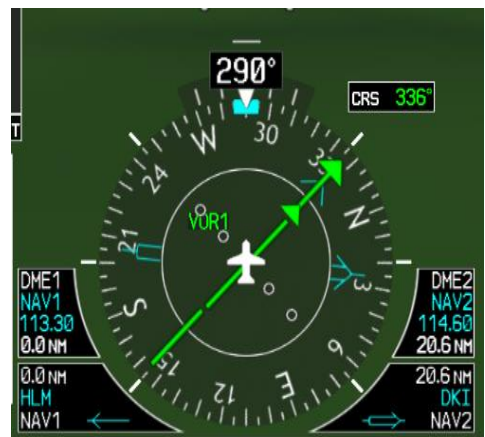

Gambar 13A Perbandingan Visualisasi Instrument HSI - GIFD Trainer

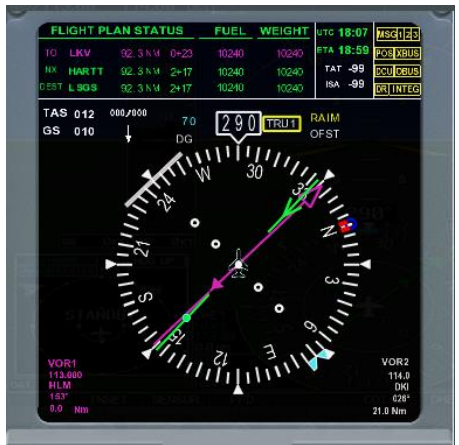

Gambar 13B Perbandingan Visualisasi Instrument $\mathrm{HSI}$ - Perangkat Lunak

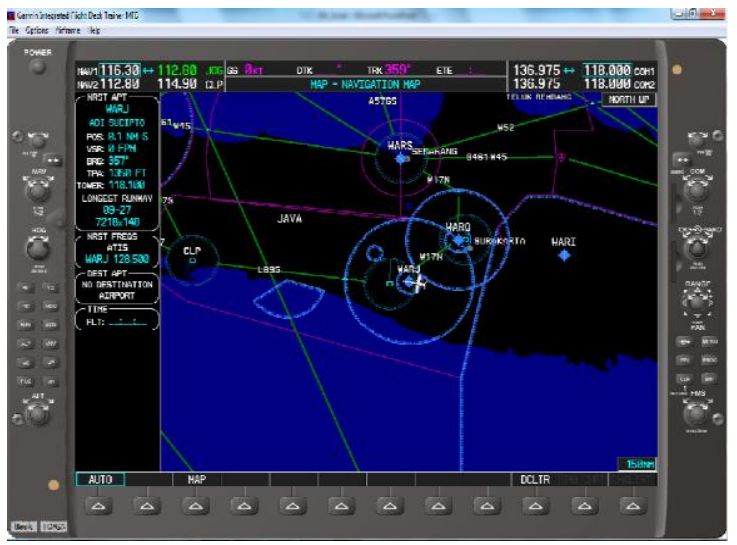

Gambar 14 A. GIFD Trainer Bandara Adi Sucipto-MFD

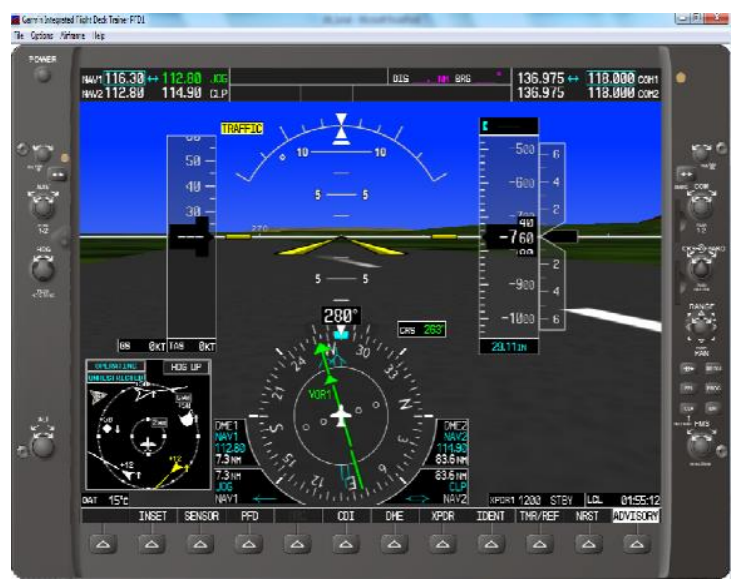

Gambar 14 B. GIFD Trainer Bandara Adi Sucipto-PFD

Hasil visualisasi dengan menggunakan data input yang sama, heading $280^{\circ}$, menggunakan VOR HLM dan VOR CLP dengan perangkat lunak yang dikembangkan dapat ditunjukkan hasil simulasinya seperti Gambar 15.

Gambar 15A dan 15 B dengan menggunakan input yang sama dengan perangkat GIFD Trainer, pada map dapat divisualisasikan pesawat terbang berada pada Adi Sucipto (WARJ), jarak pesawat dengan VOR JOG adalah $7 \mathrm{Nm}$ dengan bearing pesawat terhadap JOG adalah $264^{\circ}$, sementara jarak pesawat dengan CLP adalah $87 \mathrm{Nm}$ dengan bearint $275^{\circ}$.

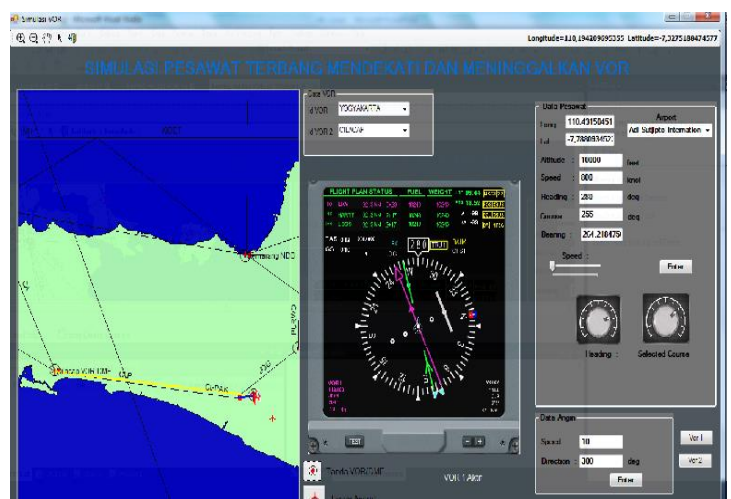

Gambar 15 A. Perangkat Lunak Simulator VOR dari Bandara Adi Sucipto - JOG 


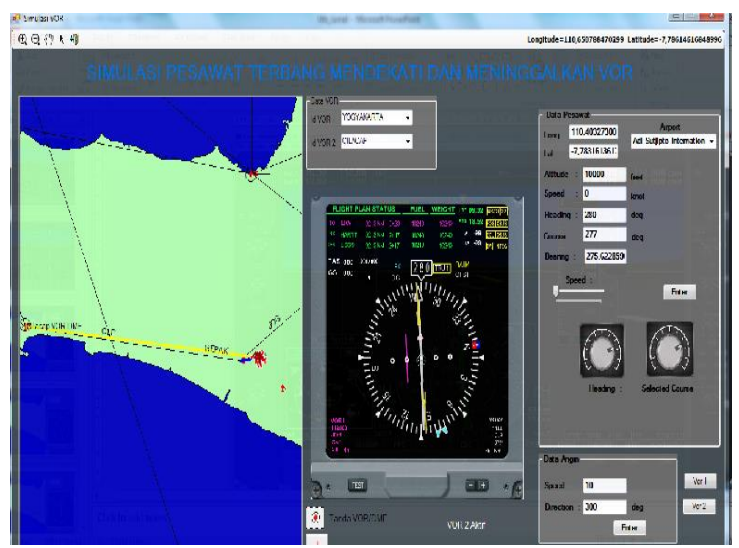

Gambar 15 B. Perangkat Lunak Simulator VOR dari Bandara Adi Sucipto - CLP

Hasil simulasi GIFD Trainer dibandingkan dengan menggunakan perangkat lunak yang dikembangkan dengan menggunakan input yang sama untuk VOR JOG, dapat divisualisasikan pada instrumen $\mathrm{HSI}$ seperti Gambar 16.

Gambar 16 A hasil simulasi dengan GIFD Trainer jarak pesawat dengan VOR JOG 7.3 Nm, bearing $263^{\circ}$ dan course $263^{\circ}$. Gambar 16B hasil simulasi dengan menggunakan perangkat lunak yang dikembangkan. jarak dengan VOR JOG adalah $7 \mathrm{Nm}$, bearing $264^{\circ}$, course $264^{\circ}$ seperti ditunjukkan panah hijau.

\section{Hasil simulasi GIFD Trainer dibandingkan dengan menggunakan} perangkat lunak yang dikembangkan dengan menggunakan input yang sama untuk VOR CLP, dapat divisualisasikan pada instrumen HSI seperti Gambar 17.

Hasil simulasi dengan GIFD Trainer jarak pesawat dengan VOR CLP 83.6 Nm, bearing $274^{\circ}$ dan course $96^{\circ}$ panah hijau (GIFD Trainer). Hasil simulasi dengan menggunakan perangkat lunak yang dikembangkan. jarak dengan VOR CLP adalah $86 \mathrm{Nm}$, bearing $275^{\circ}$, course $96^{\circ}$ seperti ditunjukkan panah putih (Simulator VOR).

Aplikasi Simulasi VOR dijalankan dengan mengatur speed 420 knot, hasil simulasi dapat diperlihatkan seperti pada Gambar 18.

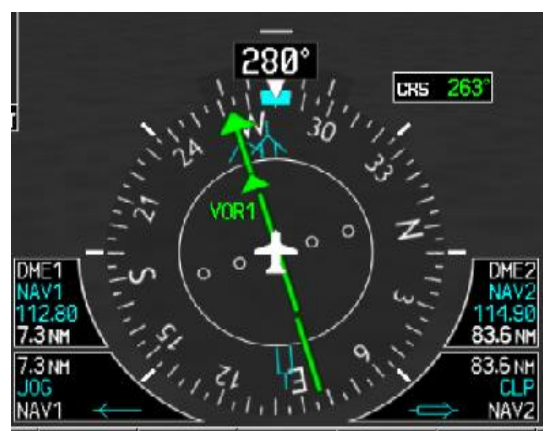

Gambar 16 A. Instrumen HSI GIFD Trainer JOG

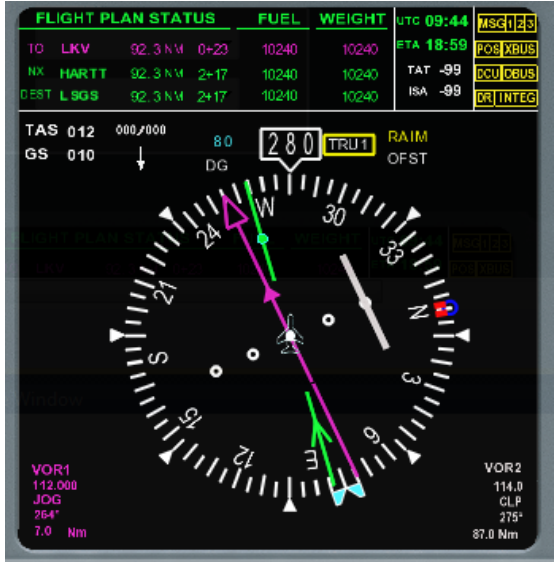

Gambar 16 B. Instrumen HSI Simulator VOR JOG

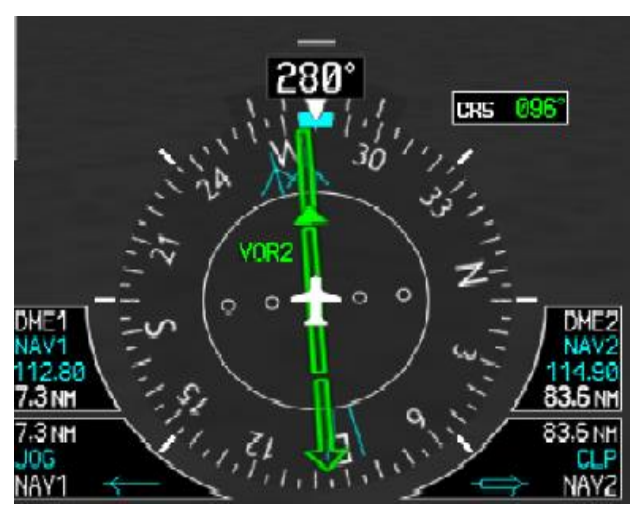

Gambar 17A Instrumen HSI GIFD Trainer CLP

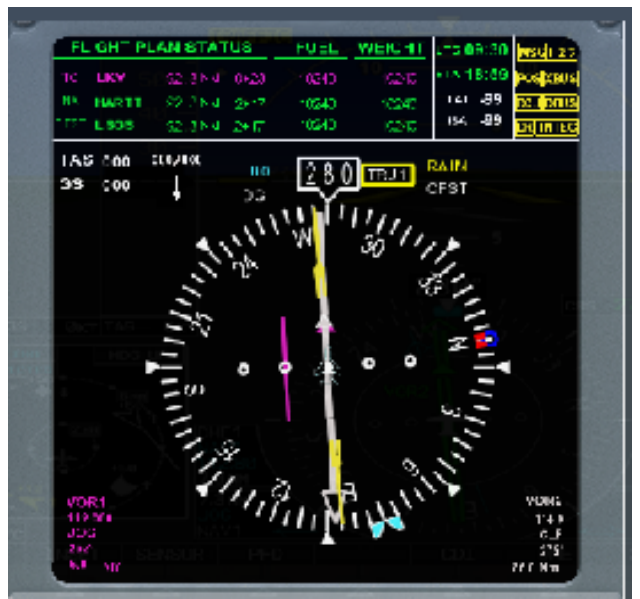

Gambar 17 B Instrumen HSI Simulator VOR CLP 


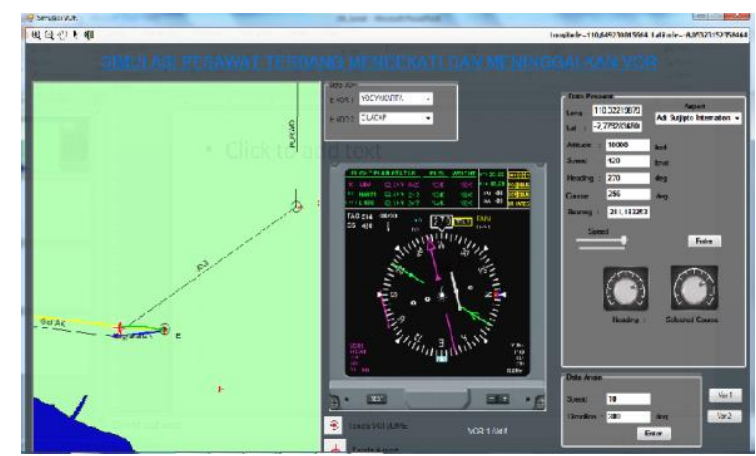

Gambar 18 A Simulasi Dengan Speed 420 knot sebelum melewati JOG jarak $1 \mathrm{Nm}$

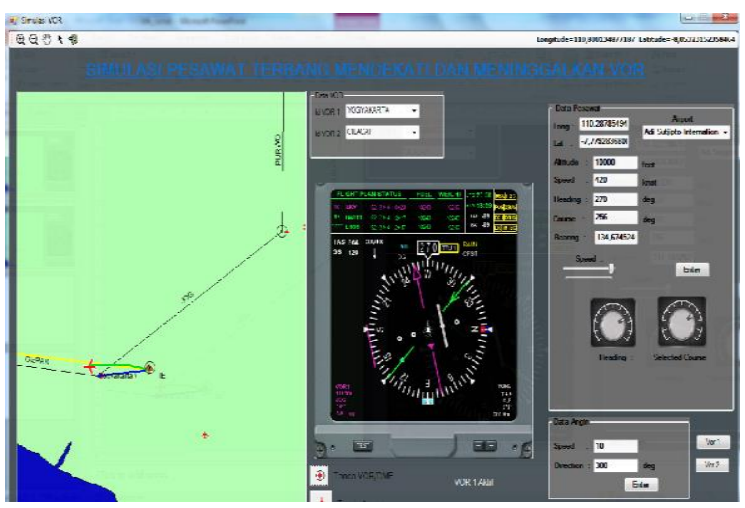

Gambar 18 B Simulasi Dengan Speed 420 knot setelah melewati JOG jarak $1 \mathrm{Nm}$

Heading pesawat $270^{\circ}$, bearing $211^{\circ}$ dengan course $256^{\circ}$ tanda pergerakan pesawat garis hijau pada peta. Tanda from/to pada instrument tetap menunjukkan to (menuju) JOG, setelah melewati JOG tanda from/to berubah seperti gambar, bearing pesawat terhadap JOG $134^{\circ}$.

Pesawat disimulasikan tetap terbang dengan speed 420 knot untuk mencapai CLP sebagai VOR tujuan berikutnya

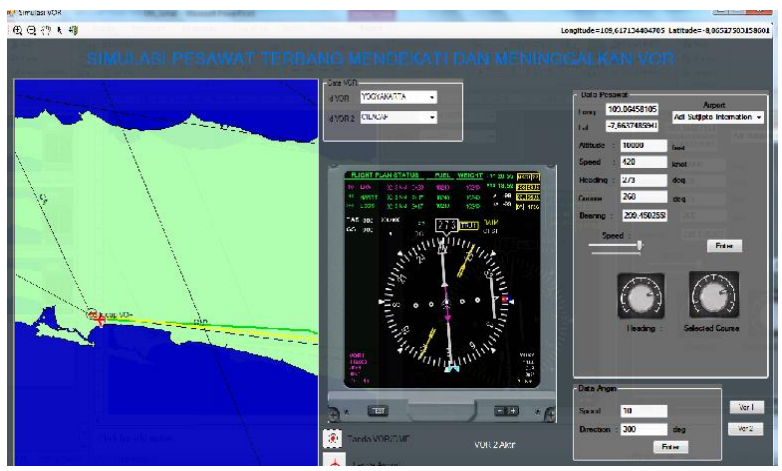

Gambar 19. Simulasi Dengan Speed 420 knot sebelum melewati CLP jarak $2 \mathrm{Nm}$
Gambar 19 memvisualisasikan pesawat sebelum melewati CLP pada jarak $2 \mathrm{Nm}$, bearing $299^{\circ}$, tanda from/to menunjukkan to CLP.

Perbesaran gambar HSI dapat diperlihatkan pada Gambar 20.

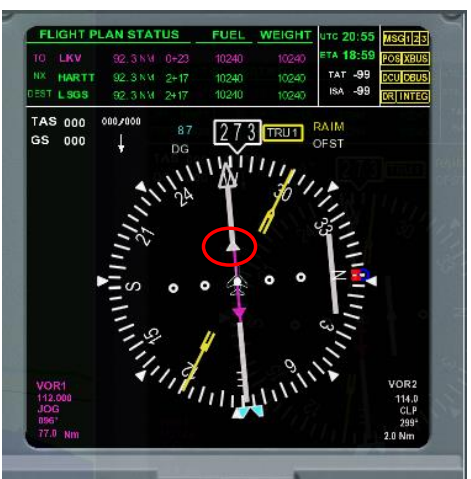

Gambar 20. HSI sebelum pesawat melewati CLP jarak $2 \mathrm{Nm}$

Pesawat disimulasikan tetap terbang dengan speed 420 knot sampai melewati CLP seperti pada Gambar 21.

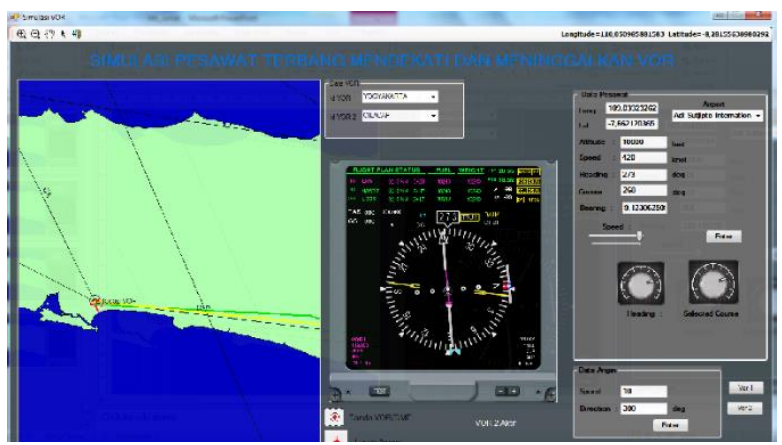

Gambar 21. Simulasi Dengan Speed 420 knot tepat melewati CLP jarak $0 \mathrm{Nm}$

Gambar 21 memvisualisasikan pesawat tepat melewati CLP dengan jarak $0 \mathrm{Nm}$, bearing $9^{0}$, tanda from/to menunjukkan from CLP.

Perbesaran gambar HSI dapat diperlihatkan pada Gambar 22. 


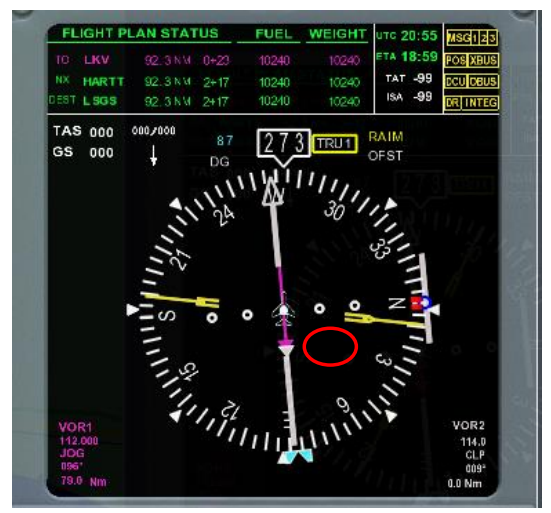

Gambar 22. HSI tepat pesawat melewati CLP jarak $0 \mathrm{Nm}$

\section{KESIMPULAN DAN SARAN}

\section{Kesimpulan}

Setelah melakukan rancang bangun perangkat lunak Simulator VOR, penulis mengambil kesimpulan sebagai berikut :

1. Instrument $\mathrm{HSI}$ yang dikembangkan sesuai dengan perangkat lunak lain dalam hal ini Garmin Integrated Flight Deck (GIFD) Trainer.

2. Hasil visualisasi HSI pada perangkat lunak Simulator VOR yang dikembangkan dengan input yang sama menunjukkan hasil yang sama dengan GIFD.

3. Jarak dan bearing antara pesawat dengan VOR/DME menunjukkan hasil yang sama dengan GIFD, jika ada perbedaan karena posisi latitude dan longitude VOR/DME GIFD tidak diketahui.

4. Visualisasi map dapat diperbesar untuk menampilkan lebih jelas pergerakan pesawat mendekati VOR/DME.

\section{Saran}

Navaids dalam penerbangan selain menggunakan VOR/DME digunakan juga NDB atau ADF. Dengan menggunakan VOR/DME dan NDB pesawat dapat menentukan arah terbang sehingga dapat mencapat tujuan. Sehingga untuk melengkapi perasngkat lunak Simulator VOR/DME harus dilengkapi dengan NDB atau ADF.

\section{DAFTAR PUSTAKA}

1. Nurlaili Wulan Sari, Bekti Yulianti. Analisa Fungsi T-DME Sebagai Pengganti Fungsi Outer Marker Runway O7 L Bandara Soekarno Hatta. Jurnal Teknologi Industri Vol 7, No 1. Unsurya. 2019

2. Susi Diriyanti Novalina, Abd Rachman Abubar, Rossi Peter Simanjuntak. Rancangan Simulasi Visual Untuk Menampilkan Prinsip Kerja DVOR Menggunakan Visual Studio Sebagai Media Pembelajaran Di Akademi Teknik Dan Keselamatan Penerbangan Medan. Jurnal IImiah Dunia Ilmu Vol 5 No 1 April 2019.

3. Fahrul Agus, Dedy Fuadi, Yunizar Fahmi Badron. Sistem Informasi Geografi untuk Simulasi Rute Penerbangan Virtual. Jurnal Infotel Vol.9 No.1. Februari 2017.

4. Diego Widagdo, 2014. Peralatan Navigasi dalam Penerbangan. https://diegowidagdo.wordpress.com/ 2014/12/21/p eralatan-navigasidalam-penerbangan/

5. ICAO Training Department Headquarters, Introduction to Navigation Version 1.0, 2014

6. Susanto, Arip, 2015, Navigasi Udara, http://www.aripsusanto.com/p/naviga si-udara.html

7. GL STUDIO, GlsPlayer 4.0.9.0, User's Manual Version 4.0.9.0.a Doc. Number GLSPLYR-0001 rev a.

8. PTDI.Software Design Description of OGNT Server For Tentera Udara Diraja Malaysia (TUDM) Document No 35/NTM1/NT1100/ 08/008. Malaysia. 2008.

9. PT. Dirgantara Indonesia. 2009. Syllabus and Study Guide Trainee and Instructor Guide.

10. Williams, Ed, Aviation Formulary $V$ 1.46. 2015

https://edwilliams.org/avform.htm 
